\title{
Migration of Conductive Ink using Silver-Copper Solid Solution Powder
}

\author{
Member Satoshi Fujiki \\ (Toyama Industrial Technology Center) \\ Member Katsumi Tanino \\ (Toyama Industrial Technology Center) \\ Non-member Jiro Sato \\ (Asahi Chemical Industry Co. Ltd.) \\ Non-member Chiei Tatsuyama (Toyama University)
}

\begin{abstract}
Summary
We developed the conductive ink using silver $(\mathrm{Ag})$-copper $(\mathrm{Cu})$ solid solution powder and investigated an ionic migration phenomenon of the conductive ink. The conductive ink is made by dispersing the powder in phenol resin. This powder has a shell structure. The Ag concentration at the surface of the powder is higher than an average Ag concentration in the bulk, and $\mathrm{Ag}$ concentration decreases toward inside of the powder. The $\mathrm{Ag}$ concentration of about $85 \mathrm{wt} \%$ in the Ag-rich phase dose not strongly depend on the average $\mathrm{Ag}$ concentration, and the thickness of $\mathrm{Ag}$-rich phase increase with the average $\mathrm{Ag}$ concentration. Though this ink includes $\mathrm{Ag}$, in which ionic migration occurs most easily, and $\mathrm{Cu}$, which is oxidized easily, the migration occurrence of this ink including the powder with $\mathrm{Ag}$ of $5 \mathrm{wt} \%$ was similar to that of $\mathrm{Cu}$ conductive ink and $\mathrm{Ag}$ migration was not observed.
\end{abstract}

Keywords: migration, silver-copper solid solution powder, conductive ink, graded structure

\section{Introduction}

A failure occurs occasionally when electronic components are operated for a long time on field use. One of these failure includes an insulating breakdown at low electric field under humid environment, and this type of failure causes a short- circuit eventually. Such a phenomenon first reported in detail by Kohman in 1955 [1]. He found that this insulating failure was accompanied with the movement of the contact metal on or inside the substrate insulator. It was concluded that this metal transports, named "silver migration", occurs by an electrochemical mechanism in which a metal element on high potential conductor is ionized under the existence of water and the ion is moved on the insulator toward low potential conductor, and the metal precipitates on the substrate between conductors.

Further, the generation of conductive anodic filaments (CAF) was found, in which the metal precipitates on the surface of fiber in the epoxide insulator. It was also found that the migration depends strongly on the environmental conditions, such as temperature, humidity and electric field [2-4].

On the other hands, in order to lower a cost of consumer electronic products, a conductive ink is printed with screen mask, and hardened at a low temperature in the air for making wiring. It is widely used that a conductive ink is made by dispersing $\mathrm{Ag}$ or $\mathrm{Cu}$ powders in a resin. An electric characteristic of $\mathrm{Ag}$ conductive ink is satisfactory due to its low specific resistivity. However, there is a demerit that a migration occurs easily in Ag. Although $\mathrm{Cu}$ conductive ink is superior than $\mathrm{Ag}$ conductive ink because of lower trend of the migration, it is easily oxidized.

To overcome these problems, in the present work, the conductive ink containing $\mathrm{Ag}-\mathrm{Cu}$ solid solution ( $\mathrm{SCSS}$ ) was developed [5]. In this powder, $\mathrm{Ag}$ concentration at the surface is higher than inside of the powder. The migration characteristics of this conductive ink will be compared with $\mathrm{Ag}, \mathrm{Cu}$ and $\mathrm{Ag}-\mathrm{Cu}$ mixed conductive ink, and the migration mechanism of SCSS ink will be discussed.

\section{Experimental Methods}

\subsection{Experimental samples}

The sample used in the present experiment are listed in Table 1, where composit and powder state of each sample is shown. After dissolving $\mathrm{Ag}$ into $\mathrm{Cu}$, SCSS powder was made by atomizing method in non-active nitrogen gas. The composition ratios of $\mathrm{Ag}$ were 5 and 20,30,40,85 wt\%, these are named $F, G, H, I$ and $J$ respectivily in Table 1 . SCSS conductive ink was made by mixing and dispersing these powders in phenol resin (resorcinol type) using automatic mortar. Grycol ether was used as solvent. For a comparison with SCSS ink, we also made conductive ink, consisting of mixed powders of $\mathrm{Ag}$ and $\mathrm{Cu}$ (MSC). The mixing ratios of $\mathrm{Ag}$ in MSC ink were 2.5 and 5, 10, $20 \mathrm{wt} \%$ and named B,C,D,E respectively in Table 1 . The pure $\mathrm{Cu}$ 
(named $\mathrm{A}$ ) and pure $\mathrm{Ag}$ ( $\mathrm{K}$ and $\mathrm{L}$ ) were also tested. A paper phenolic board was used for an insulation substrate. The gap for electrodes, which were printed directly on the substrate with screen mask, was $0.5 \mathrm{~mm}$ ( $30 \mathrm{~mm}$ in length) and the specimen was hardened in a furnace at $150^{\circ} \mathrm{C}$ for 30 minutes in the air by using an electric oven.

\subsection{Testing methods}

Figure 1 shows a steady test method with a circuit for measuring insulation resistance under a damp heat environment. In order to cause a migration, specimen was left in the condition of steady temperature $\left(40,65\right.$ and $\left.85^{\circ} \mathrm{C}\right)$ and steady humidity (95\%R.H.) for about 500 hours. The applied voltage between electrodes was DC $100 \mathrm{~V}$. A change of value of an insulation resistance was recorded by a multi-plotter. For observing the migration, optical microscope and scanning electron microscope (SEM) were used after the test. Electron probe micro analysis (EPMA) (Hitachi S-2700 and Horiba EMAX5770), field

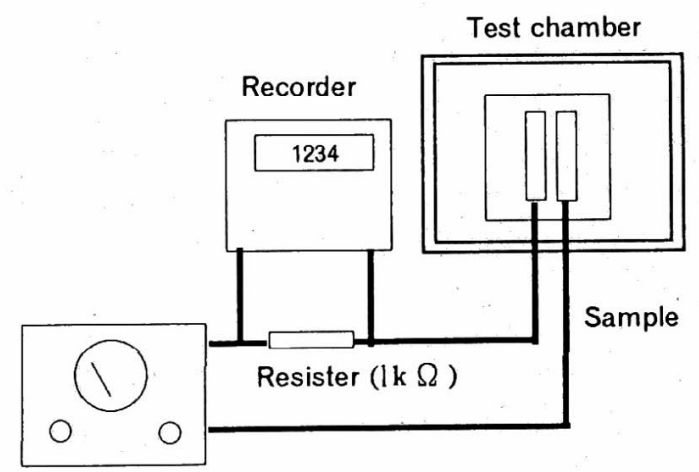

Power supply (DC 100V)

Fig.1. Testing method of migration and resistance.

Table 1. Component and powder state of conductive ink.

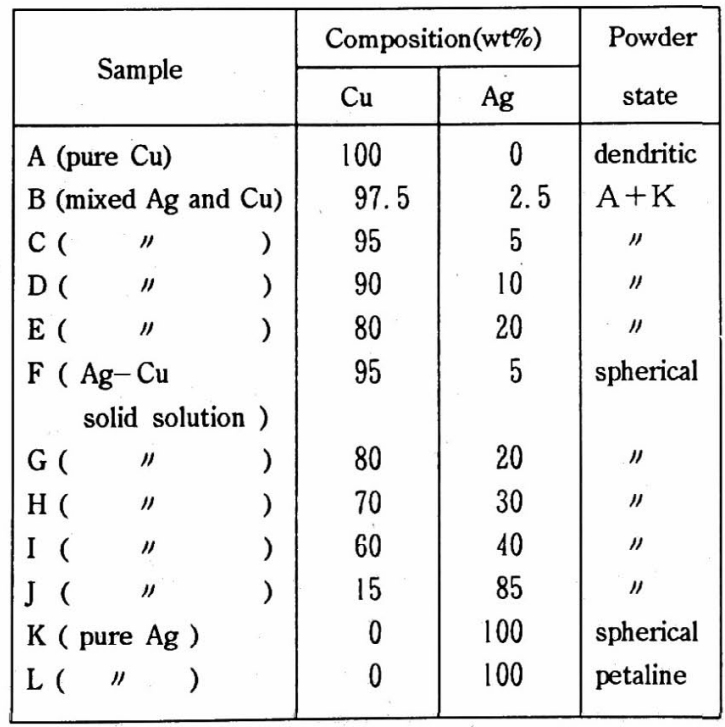

emission transmission electron microscopy (FE-TEM) (Hitachi HF2000) and X-ray photoelectron spectroscopy (XPS) (ULVAC Model5400) ) were used to estimate the metal composition, and $\mathrm{X}$-ray diffractmeter (XRD) (Rigaku RAD-B) using $\mathrm{Cu}-\mathrm{K} \alpha$ $(1.541 \AA)$ was used to analyze the crystal structure of powders.

\section{Results and Discussion}

\subsection{Structural analysis}

Figure 2 shows SEM images of the various printed conductors. As shown in Figs.2(a) and (b), SCSS conductive powder and $\mathrm{Ag}$ powder used for MSC ink have spherical shape with diameter of an approximately less than $10 \mu \mathrm{m}$. A shape of $\mathrm{Cu}$ powder (Fig.2(c)) in $\mathrm{Cu}$ conductive ink is dendritic. The conductive ink can not be made by $\mathrm{Cu}$ powder with spherical shape because of the poor contact between powders. The typical shape of $\mathrm{Ag}$ powder used for $\mathrm{Ag}$ conductive ink is petaline, as shown in Fig.2 (d).
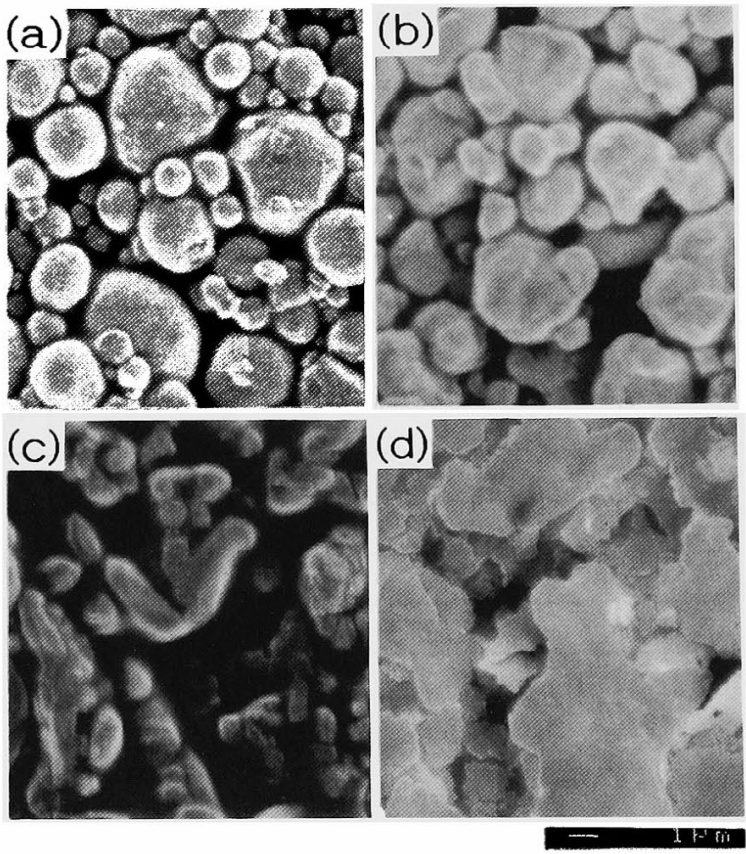

Fig.2. SEM view of several samples, (a) SCSS Ag-5 wt\% of sample $\mathrm{F}$, (b) spherical $\mathrm{Ag}$ of sample $\mathrm{K}$, (c) dendritic $\mathrm{Cu}$ of sample $\mathrm{A}$, (d) petaline $\mathrm{Ag}$ of sample $\mathrm{L}$.

Figure 3 shows the distribution of $\mathrm{Ag}$ on a powder surface in a sample F (SCSS, Ag-5 wt\%) observed by FE-TEM. It is found that a powder consists of several grains, and $\mathrm{Ag}$ piles up in large quantities on grain boundaries. XPS revealed that the $\mathrm{Ag}$ concentration on the powder surface in this sample is about $35 \%$, which is much higher than the average Ag concentration of $5 \%$. Metal compositions estimated by the integral intensity of $\mathrm{Ag3d}$ and $\mathrm{Cu} 2 \mathrm{p}$ lines in XPS specrum, taking into account the relative sensitivity of these lines. These results suggest that $\mathrm{Ag}$ is 
concentrated at the surface, and the powder has a gradedcomposition structure in which $\mathrm{Ag}$ concentration decreases towards inside.

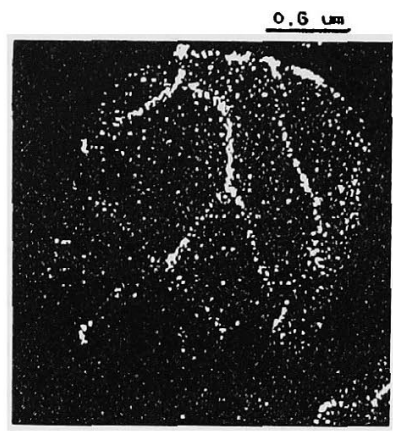

Fig.3. Ag map for SCSS powder of sample F (Ag-5 wt\%) observed by FE-TEM.

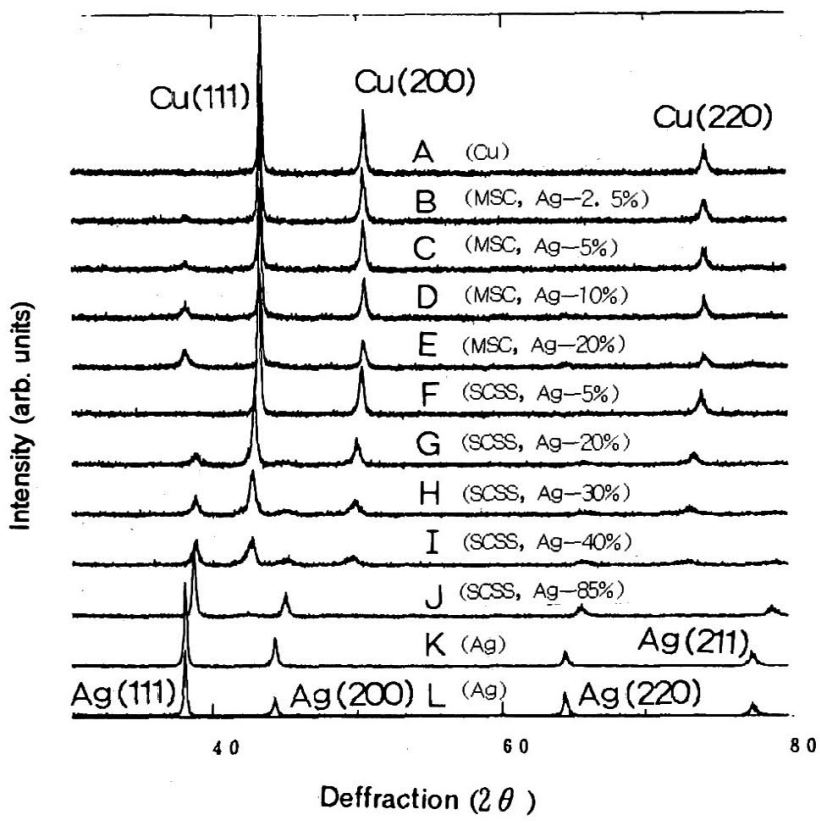

Fig.4. X-ray diffraction patterns of the samples.

Figure 4 shows XRD patterns of the samples. The powders are polycrystalline. It is found that the diffraction peaks related to $\mathrm{Ag}$ and $\mathrm{Cu}$ coexist in one sample, suggesting the presence of two phases of solid solutions in SCSS powders. One of which is a $\mathrm{Ag}$-rich phase in which $\mathrm{Cu}$ is dissolved into $\mathrm{Ag}$, and the other is a $\mathrm{Cu}$-rich phase in which $\mathrm{Ag}$ is dissolved into $\mathrm{Cu}$. It is interesting to note that the positions of the diffraction peaks related to $\mathrm{Ag}$ and $\mathrm{Cu}$ do not depend on $\mathrm{Ag}$ concentration in MSC samples (A-F), on the other hand, these peaks in SCSS samples (F-J) shift depending on the Ag concentration.

Figure 5 shows the relationship between $\mathrm{Ag}$ concentration and lattice constants calculated from $\mathrm{Cu}(111)$ and $\mathrm{Ag}(111)$ peaks in Fig.4, where the $\mathrm{Ag}$ concentration is changed from $\mathrm{wt} \%$ to mol\%. The lattice constant of Ag-rich phase shows the large deviations from that of $\mathrm{Ag}$ with addition of $\mathrm{Ag}$ of $3 \mathrm{~mol} \%$ ( 5 $w t \%)$ in the powder. However, it does not strongly depend on further increase in the average $\mathrm{Ag}$ concentration. On the other hand, the lattice constant of Cu-rich phase increases gradually with increase in $\mathrm{Ag}$ concentration. However, it also tend to saturate over $20 \mathrm{~mol} \%$ ( $30 \mathrm{wt} \%$ ). If Vegard's law is applied to the results shown in Fig.5, we can estimate $\mathrm{Ag}$ and/or $\mathrm{Cu}$ concentrations in these phases. For example, in a sample $\mathrm{F}$ (Ag-3 mol\%) and $\mathrm{J}(\mathrm{Ag}-77 \mathrm{~mol} \%$ ), the $\mathrm{Ag}$ concentrations in Ag-rich phase are about 83 and $87 \mathrm{~mol} \% \quad$ (89 and $92 \mathrm{wt} \%$ ), respectively, and they are about 3 and $14 \mathrm{~mol} \% \quad(4$ and 22 $w t \%)$ in $\mathrm{Cu}$-rich phase, respectively. The $\mathrm{Ag}$ concentrations in these two phases do not coincide with the average $\mathrm{Ag}$ concentrations. The phase with higher Ag concentration should exist on the surface of powders, as expected from the XPS measurements. These results indicate that SCSS powder has a shell structure in which Ag-rich solid solution layer exist at the surface of $\mathrm{Cu}$-rich solid solution core. The thickness of Ag-rich phase increases keeping about the same $\mathrm{Ag}$ concentration for the increase in the average $\mathrm{Ag}$ concentration in the powder. The situation is also similar to $\mathrm{Cu}$-rich phase except the low $\mathrm{Ag}$ concentration region, that is, only the volume of $\mathrm{Cu}$-rich phase with about the same composition decreases with increase in the average $\mathrm{Ag}$ concentration.

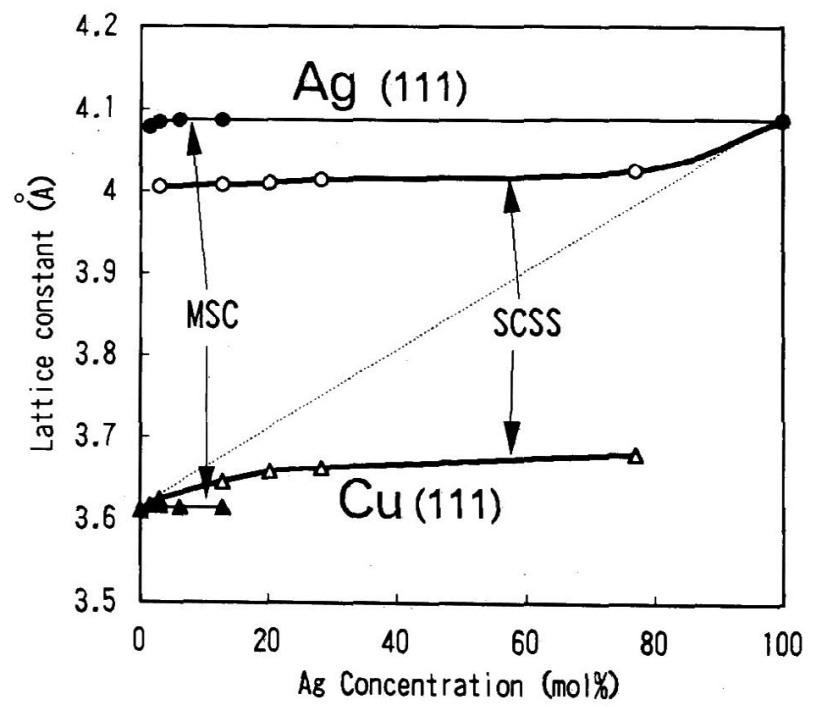

Fig.5. Relations between lattice constant and $\mathrm{Ag}$ concentration.

\subsection{Migration characteristics}

\subsubsection{Observation by optical microscope}

Figure 6 shows the observation of migration by optical microscope after keeping specimen for 1000 hours at the condition of $40^{\circ} \mathrm{C}, 95 \%$ R.H.. As seen in the figures, migration is observed between conductors after the test irrespective of a kind 
of conductive ink. It was found that the type of migration is the so called CAF (Conductive Anodic Filaments), where migration occurs like a filament along a fiber in the base material from an anode, and it is not observed on its surface.

In the specimens of SCSS, the number of CAF and quantity of moved metal increases with increase in $\mathrm{Ag}$ concentration, as shown in Figs.6 (c), (e), (g) and (i). This trend is also observed in the specimens of MSC, as shown in Figs.6(d) and (f). Though the migration occurs in $\mathrm{Cu}$ sample too, as shown in Fig.6 (b), CAF due to migration is a little. In the specimens of $\mathrm{Ag}$ shown in Figs.6(h) and $(j)$, migration occurs more remarkably than in specimens of SCSS, as suggested by many CAF. The edges of these conductors discolor black, may be due to the oxidation. It is found that the shape difference of $\mathrm{Ag}$ powder
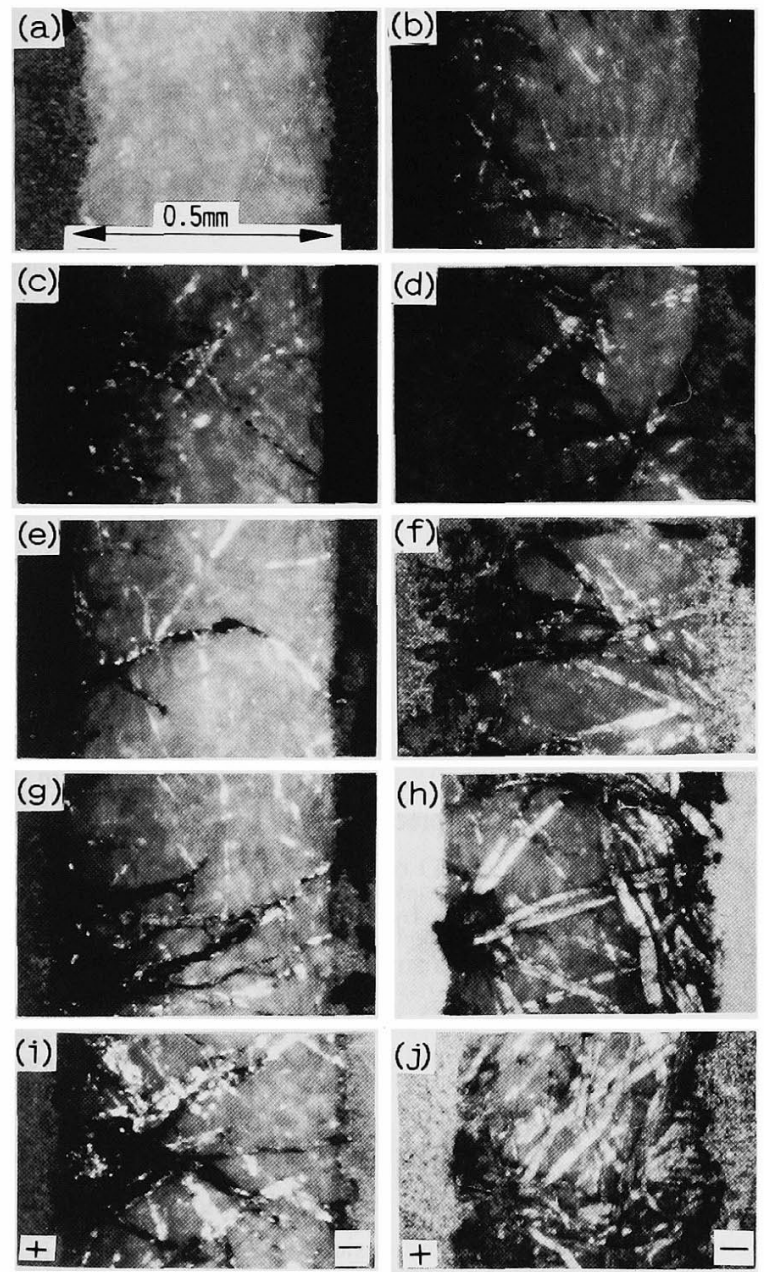

Fig.6. Optical view of migration of samples exposed to the moisture of $40^{\circ} \mathrm{C}, 95 \%$ R.H. at $200 \mathrm{~V} / \mathrm{mm}$ for 1000 hours, (a) as prepared, (b) pure Cu of sample A, (c) ScSS Ag-5 wt\% of sample F, (d) MSC Ag-5 wt\% of sample C, (e) SCSS Ag-20 wt\% of sample G, (f) MSC Ag-20 wt\% of sample E, (g) SCSS Ag-30 wt\% of sample $H$, (h) spherical $\mathrm{Ag}$ of sample K. (i) ScSS Ag-40 wt\% of sample I, ()) petaline Ag of sample $\mathrm{L}$. The polarity of an applied voltage is shown in the figure. dose not affect on the degree of migration, because the occurrence of migration of both $\mathrm{Ag}$ conductors shown in Figs.6. (h) (spherical-shaped) and (j) (petaline-shaped) are similar.

\subsubsection{Change of insulation-resistance value}

Figure 7 shows the changes of insulation-resistance value with time under a wet-proof test in condition of $40^{\circ} \mathrm{C}, 95 \%$ R.H.. In a few minutes after the starting of the test, the resistance value decreases quickly several orders from about $10^{12}$ to $10^{8} \Omega$ by the absorption of moisture, and then it holds on stable state. After certain period of time, the value of resistance goes down rapidly. It is considered that this rapid drop of resistance is due to the formation of the conductive path of precipitated metal caused by migration. The value of resistance goes lower unstably with repeating up and down by the progress of migration with time. Here, we defined a time when the resistance value becomes 1 order lower than that of first value after moisture absorption as a failure time.

Figure 8 shows relationship between failure time and $\mathrm{Ag}$ concentration. In the figure, the solid line shows failure times of SCSS and dashed line represents failure times of MSC. Failure times of $\mathrm{Ag}$ ( $\mathrm{L}$ and $\mathrm{K}$ ) are shortest, and failure time of $\mathrm{Cu}(\mathrm{A})$

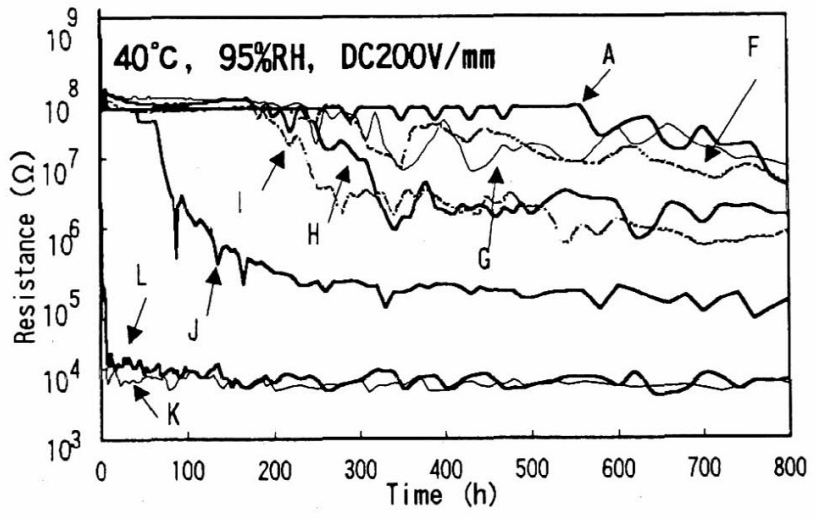

Fig.7. Change of resistance with time under a wet-proof test for various conductive ink.

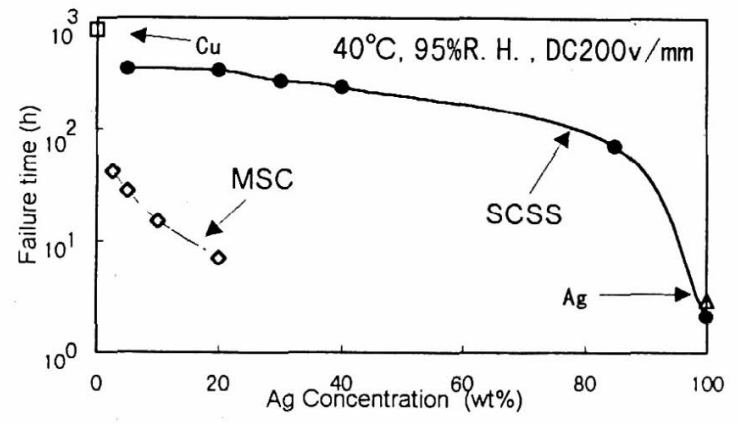

Fig. 8 Relationships between $\mathrm{Ag}$ concentration and failure times. 
is longest as compared with the other specimens. As $\mathrm{Ag}$ concentration increases in SCSS specimens, a failure time is shortened. The failure time of MSC decreases rapidly at high $\mathrm{Ag}$ concentration. In comparison with samples of the same concentration of $\mathrm{Ag}$, it is clear that the migration occurs easier in MSC than in SCSS.

Figure 9 shows that the temperature dependence of failure time of various conductive ink. A failure time by migration can be formularized by the following experimental expression [6],

$$
\mathrm{t}_{\text {MTTF }}=\mathrm{a}(\mathrm{H})^{\mathrm{b}} \exp \left(\mathrm{Ea} / \mathrm{kB}_{\mathrm{B}} \mathrm{T}\right) \text {, }
$$

where $t_{\text {MrTr }}$ is a mean failure time $(h), a, b$ and $d$ are constants, $H$ is a relative humidity, $\mathrm{E}_{\mathrm{a}}$ is an activation energy $(\mathrm{eV}), \mathrm{k}_{\mathrm{B}}$ is Boltzman constant, $\mathrm{T}$ is an absolute temperature $(\mathrm{K})$.

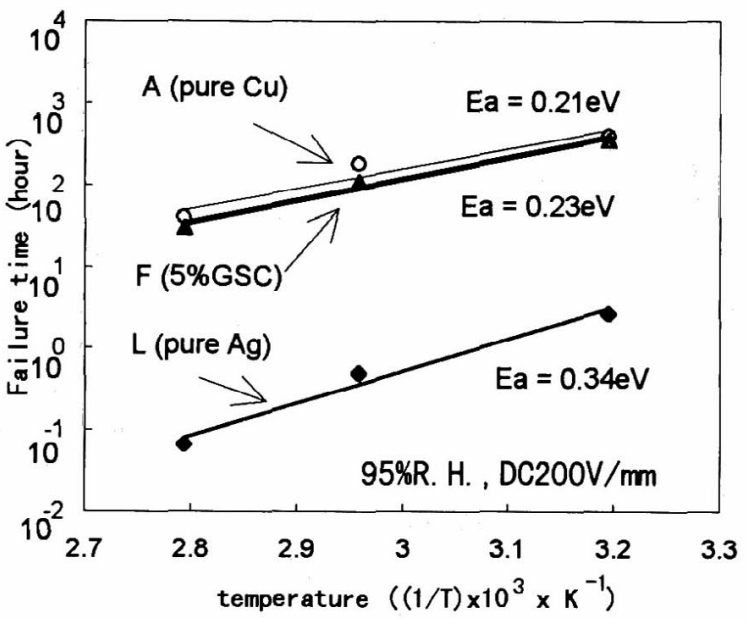

Fig.9. Arthenius plot of the temperature dependence of failure time of various conductive ink ( $E a=a c t i v a t i o n$ energy).

An activation energy of sample $\mathrm{F}$ (SCSS, $\mathrm{Ag}-5 \mathrm{wt} \%, \mathrm{Ea}=$ $0.23 \mathrm{eV}$ ) is nearly equal to that of specimen $\mathrm{A}$ (pure $\mathrm{Cu}, \mathrm{Ea}=$ $0.21 \mathrm{eV}$ ). The value of specimen $\mathrm{L}$ (pure $\mathrm{Ag}$ ) is $0.34 \mathrm{eV}$. This result indicates that the changing mechanism of resistance value of SCSS ink including $\mathrm{Ag}$ of $5 \mathrm{wt} \%$ is similar to that of $\mathrm{Cu}$ ink. Namely, it means that $\mathrm{Ag}$ in SCSS powder is not practically influential for a cause of the drop of insulation resistance.

\subsubsection{Elemental analysis}

Figure 10 shows the examples of elemental distribution map observed by EPMA between conductors of sample F (SCSS, AG-5 wt\%) after a migration test for 1000 hours. As shown in Fig.10(c), $\mathrm{Ag}$ is not detected in EPMA analysis of the place where migration is seen by SEM photograph ( Fig.10(a)). Only $\mathrm{Cu}$ is detected in the same area as shown in Fig.10(b). Although it is undeniable that $\mathrm{Ag}$ exists less than a detection sensitivity, it is considered that almost $\mathrm{Ag}$ dose not migrate because of immovable state in solid solution.
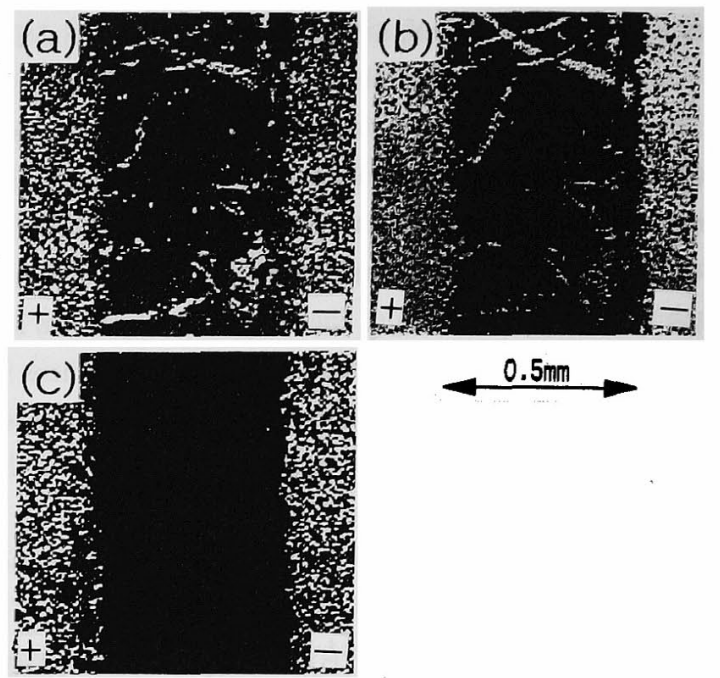

$0.5 \mathrm{~mm}$

Fig. 10. EPMA photographs of sample $F$ after migration test, (a) SEM photograph of migration, (b) Cu-K $\alpha$ map of the same area (a), (C) Ag- $\mathrm{L} \alpha$ map of the same area (a). The polarity of an applied voltage is shown in the figure.

\subsubsection{Migration mechanism of SCSS ink}

$\mathrm{Ag}$ migration mechanism of forming $\mathrm{CAF}$ may be expressed by the following reaction formulae $[1],[7]$.

$$
\begin{aligned}
& \mathrm{Ag} \rightarrow \mathrm{Ag}^{+}+\mathrm{e}^{-} \\
& \mathrm{H}_{2} \mathrm{O}+\mathrm{e}^{-} \rightarrow 1 / 2 \mathrm{H}_{2}+\mathrm{OH}^{-} \\
& \mathrm{Ag}^{+}+\mathrm{OH}^{-} \rightleftharpoons \mathrm{AgOH} \\
& 2 \mathrm{AgOH} \rightleftharpoons \mathrm{Ag}_{2} \mathrm{O}+\mathrm{H}_{2} \mathrm{O} \\
& \mathrm{Ag}_{2} \mathrm{O}+\mathrm{H}_{2} \rightarrow 2 \mathrm{Ag}+\mathrm{H}_{2} \mathrm{O}
\end{aligned}
$$

As shown by a formula (2), under the electric field, Ag is ionized at the anode, and $\mathrm{Ag}^{+}$moves toward cathode in the water on the substrate. $\mathrm{Ag}^{+}$precipitates on the substrate between the electrodes as $\mathrm{AgOH}, \mathrm{Ag}_{2} \mathrm{O}$ or $\mathrm{Ag}$, according to formulae (3) -(6) $\mathrm{Ag}_{2} \mathrm{O}$ is also reduced by light or reducing agents. The migration mechanism of $\mathrm{Cu}$ is similar to $\mathrm{Ag}$.

Though SCSS ink includes Ag, its migration characteristic, especially in sample $\mathrm{F}$, is similar to $\mathrm{Cu}$. This behavior may be explained as follows:

As referred to the standard $\mathrm{H}^{+}$electrode, the electrode potential of $\mathrm{Cu}^{2+}$ is $0.340 \mathrm{~V}, \mathrm{Cu}^{+}$is $0.520 \mathrm{~V}$, and $\mathrm{Ag}^{+}$is $0.799 \mathrm{~V}$ [8]. Namely, $\mathrm{Cu}$ can be ionized easier than $\mathrm{Ag}$. Therefore, if $\mathrm{Ag}$ and $\mathrm{Cu}$ coexist in atomic scale as in the solid solution, $\mathrm{Ag}$ can not be ionized [7].

Thus, while $\mathrm{Cu}$ migrates, the $\mathrm{Ag}$ migration may be suppressed. The degradation of migration, as shown in Fig.9, characteristic with increase in average $\mathrm{Ag}$ concentration may be due to the increase of the $\mathrm{Ag}$ pile up on the grain boundaries in the powder.

But, in case of mixed powder of $\mathrm{Ag}$ and $\mathrm{Cu}$, this reaction can not occur easily, because $\mathrm{Ag}$ and $\mathrm{Cu}$ do not contact in atomic 
scale. Thus the migration of $\mathrm{Ag}$ and $\mathrm{Cu}$ occur independently in the mixed powder.

\section{Conclusion}

In this study, we developed the graded $\mathrm{Ag}-\mathrm{Cu}$ solid solution (SCSS) powder, and investigated an ionic migration of the conductive ink using by this powder. It was found that this powder has a shell structure in which $\mathrm{Ag}$ rich solid solution layer exists on the surface of $\mathrm{Cu}$ rich solid solution core.

The occurrence of migration of conductive ink using this SCSS powder including $\mathrm{Ag}$ of $5 \mathrm{wt} \%$ was nearly equal to $\mathrm{Cu}$.

The present result will open a way to develop the materials inhibiting effectively migration by making the solid solutions of $\mathrm{Ag}$ and $\mathrm{Cu}$ with other metals.

\section{Acknowledgements}

We express our thanks to Mr. Jun Kikuma, Asahi Chemical Industry Co. Ltd., who presented us the data of elemental analysis of powders and moved metals. We also express our thanks to Mr. Sotohiro Takabayashi, Toyama Industrial Technology Center, for cooperation in the structural analysis of samples.

(Manuscript received April 23, 1997, revised October 15, 1997)

\section{References}

[1] G. T. Kohman, H. W. Hermance and G. H. Downes: "Silver Migration in Electrical Insulation" Bell System Technical Joumal, 34, 6, 1115 (1955)

[2] D.J.Lando, J.P.Mitchell, T.L.Welsher: "Conductive Anodic Filaments in Reinforced polymeric Dielectrics Formation and Prevention", 17th Ann.Proc.Rel.Phys, 51 (1979)

[3] T.L.Welsher, J.P.Mitichell, D.J.Lando: "CAF Composite Printed-circuit Substrates: Characterization, modeling and a Resistant Material", 18th, Ann.Proc.Rel.Phys, 235 237 (1980)

[4] S.J.Krumbein: "Metallic Electromigration Phenomena", IEEE Trance. Components, Hybrids, Mfr'g Technology, 11, 5 15 (1988)

[5] A.Yokoyama, S.Nakajima: "Method of Manufacture and Application of Conductive Metalic Powder", Japan PNE, 6-72242 (1994)

[6] B.Rudra, D.Jennings: "Tutorial Failure-Mechanism Models for Conductive-Filament Formation", IEEE Trance.Rel., 43, 354 〜60 (1994)

[7] T.Yanagisawa, K.Kanou: "Migration on the Electrode for Thick Film circuit in High Humidity Environment" (in japanese), Report of Electrotechnical labolatrory, 47, 3, 147 160 (1983) [8] "Kagaku-binran" (in japanese), The Chemical Society of Japan, 466 (1993)
[9] T.Ohtori: "Mechanism and Suppression of Ion Migration in Printed Circuit Boards", The joumal of japan institute for interconnecting and packaging electronic circuits, 10, 2, 80 (1995)

\section{Satoshi Fujiki (member)}

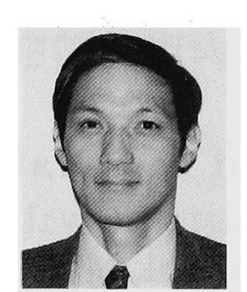

He was born in 1950. He received the B.E. degree from Toyama University in 1973. In $1975 \mathrm{He}$ joined Toyama Industrial Technology Center. He is currently engaged in the research and development of reliability of electronic parts, cooperative by multiple mobile robot, fabrication of $\mathrm{Li}$ ion secondary battery and micromachining.

\section{Katsumi Tanino (member)}

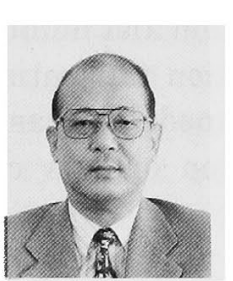

He was born in 1946. He received consulting engineering from Japan in 1983, and received the B.S. degree from Kanazawa University in 1969. In $1969 \mathrm{He}$ joined Toyama Industrial Technology Center. He received the Consulting Engineer from Japan in 1983, and Ph.D. from Tokyo Metropolitan University in 1985. He was been engaged in research and development of organic electronic materials, $\mathrm{Li}$ ion secondary battery and electrolyty solar cells.

\section{Jiro Sato (non-member)}

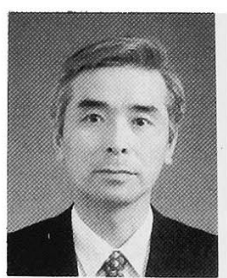

He was born in 1950 . He received the B.S. and M.S. degree from Osaka university in 1973 and 1975. In 1975 he joined Asahi Chemical Industry Co. Ltd.. He is the manager of EC Development Group in Electronics Materials and Devices Laboratory, and engaged in development of

conductiv paste.

\section{Chiei Tatsuyama (non-member)}

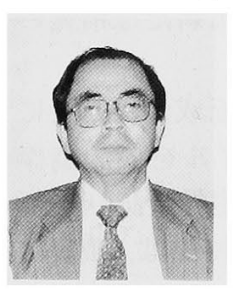

He was born in 1943. He received his Ph.D. from Osaka university in 1972. he joined Toyama university in 1972 . He is now a professor at Dpt. of Electrical and electronic system engineering, Toyama University. His research interests are Molecular Beam Epitaxy, Superlattices such as $\mathrm{SiGe}$ system, interface formations between hetero-semiconductors such as $\mathrm{GaS} / \mathrm{GaAs}$, metal and semiconductors such as $\mathrm{In}, \mathrm{Sb}, \mathrm{Al} / \mathrm{Si}, \mathrm{Ge}$. 